Calc. Tiss. Res. 4 (Supplement), 64-65 (1970)

\title{
The Effect of Cathepsins from Varied Sources on Proteinpolysaccharide (PP-L) of Bovine Costal Cartilage and on Proteoglycan Subunit (PGS) of Bovine Nasal Cartilage
}

\author{
D. D. DziewIaTKowski and V. C. HAscaLL
}

Dental Research Institute, The University of Michigan, Ann Arbor, Michigan 48104

S. W. SAJDERA

The Rockefeller University, New York, New York 10021

The death of the hypertrophic cartilage cells of epiphyseal plates may be causally linked to the provisional calcification of extraterritorial matrix in the vicinity of such cells. An increasing number of cytoplasmic organelles, limited by a single membrane and morphologically identified as lysosomes are found in maturing chondrocytes (8). Moreover, when the hypertrophic cells degenerate, the marker enzyme for lysosomes, acid phosphatase, is seen in the adjacent cartilage matrix $(1,4)$. Among the complement of enzymes in lysosomes there are acid proteases. These have been implicated as playing a role in the modification of cartilagenous matrices $(3,7,9)$. On the other hand, hydrolases released from elements of invading capillary sprouts may also have a lytic effect on the matrix (7).

In view of the two possibilities mentioned above, an acid protease isolated from bovine costal cartilage has been compared with an acid protease isolated from alveolar macrophages of rabbits as regards their effects on proteinpolysaccharide light component (PP-L) isolated from costal cartilages of calves (5) and on the proteoglycan subunit isolated from bovine nasal cartilage (6).

Thin slices of fresh costal cartilage from calves were extracted two times at $4{ }^{\circ} \mathrm{C}$ for 24 hours each time with 10 volumes of deionized water which was saturated with chloroform. After filtration through a sintered-glass filter, the filtrate was made $0.05 M$ in $\mathrm{KCl}$ and $0.005 M$ in $\mathrm{Na}_{2} \mathrm{HPO}_{4}$. The $\mathrm{pH}$ of the solution was adjusted to 7.0 by the addition of concentrated HCl. To this solution at $20^{\circ} \mathrm{C}$ a 10 per cent solution of cetylpyridinium chloride in a $0.005 M$ sodium phosphate buffer, $\mathrm{pH} 7.0$, which was also $0.05 M$ in $\mathrm{KCl}$, was slowly added with stirring until a flocculent end point was reached. The resultant precipitate was removed by filtration through a sinteredglass filter of medium porosity. Thereafter the clear filtrate was set aside at $4^{\circ} \mathrm{C}$ overnight. If excess cetylpyridinium chloride precipitated during this time, it was removed by filtration at $4^{\circ} \mathrm{C}$. The solution was dialyzed against a $0.005 M$ sodium phosphate buffer, $\mathrm{pH} 7.0$, which was also 0.05 $M$ in $\mathrm{KCl}$, for 6 hours at room temperature and then against water saturated with chloroform for 16 hours. It was next equilibrated by dialysis against a $0.005 M$ potassium acetate buffer, $\mathrm{pH} 4.0$, which was also 0.05 $M$ in $\mathrm{KCl}$.

Of the resultant retentate, $1000 \mathrm{ml}$ were passed through a $2 \times 30 \mathrm{~cm}$ column of SE-Sephadex C-25, which too had been previously equilibrated 
with the $0.05 M \mathrm{KCl}-0.005 M$ potassium acetate buffer of $\mathrm{pH} 4.0$. After washing the column with $100 \mathrm{ml}$ of the same buffer, an acid protease which could modify either PP-L or the proteoglycan subunit was eluted with a $0.05 M \mathrm{Na}_{2} \mathrm{HPO}_{4} / \mathrm{NaH}_{2} \mathrm{PO}_{4}$ buffer of $\mathrm{pH} 7.0$.

The acid protease thus concentrated from extracts of costal cartilage was further purified by gel filtration on Sephadex G-100. Fractions containing the enzyme were pooled, dialyzed against water, and lyophilized.

Alveolar machophages were harvested from rabbits 3 to 4 weeks after two injections of BCG (2). They were washed twice with large volumes of isotonic saline and then suspended in saline. The suspension of cells was frozen and thawed six times in an alcohol dry ice bath. Insoluble materials were removed by centrifugation. The extract was dialyzed against changes of water saturated with chloroform until the chloride was no longer detectable in the dialysate when a solution of silver nitrate was added. The retentate at this point was lyophilized.

The lyophilized powder was dissolved in $0.05 M \mathrm{KCl}-0.005 M$ sodium phosphate buffer, pH 7.0. Insoluble materials were removed by centrifugation and the supernatant was then treated as was the extract of costal cartilage.

Incubation of the enzyme preparations with either PP-L or PGS has been at $37^{\circ} \mathrm{C}$ and $\mathrm{pH} 4.0$, as previously reported (3). Thus far, as assessed by electrophoresis on paper and viscosimetrically the one enzyme is indistinguishable from the other on the basis of the products produced.

\section{References}

1. Cabrint, R. L.: Int. Rev. Cytol. 11, 283-306 (1961).

2. Сонn, Z. A., and E. Wiener: J. Exp. Med. 118, 991-1008 (1963).

3. Dziewlatkowski, D. D., C. D. Tourtellotte and R. D. Campo: Chemical Physiology of Mucopolysaccharides, p. 63. G. Quintakeldi, ed. Boston: Little Brown and Co. 1968.

4. Follis, R. H., and M. Berthong: Bull. Johns Hopkins Hosp. 85, 281-298 (1949).

5. Gerber, B. R., E. C. Franklin and M. Schubert: J. Biol. Chem. 235, 2870$2875(1960)$.

6. HASCAL, V. C., and S. W. SAJDERA: J. Biol. Chem. 244, 2384-2396 (1969).

7. Schenk, R. K., D. Spiro and J. Wiener: J. Cell Biol. 34, 275-291 (1967).

8. Sledge, C. B.: Clinical Orthop. 44, 241—264 (1966).

9. SledGe, C. B., and J. T. DingLe: Nature 205, 140-141 (1965). 